\title{
Caracterização textural, morfológica e estrutural de catalisadores automotivos novos e usados
}

\section{(Textural, morphological and structural characterization of new and used automotive catalysts)}

\author{
R.A.Silva, M.M. Viana, N.D.S. Mohallem \\ Laboratório de Materiais Nanoestruturados, Departamento de Química,UFMG, Belo Horizonte, MG \\ nelcy@ufmg.br
}

\begin{abstract}
Resumo
Conversores catalíticos ou catalisadores automotivos são formados por metais nobres como platina, paládio, ródio e molibdênio, suportados em filmes de alumina depositados em cordierita, um material cerâmico poroso, os quais convertem gases poluentes em dióxido de carbono, água e nitrogênio, produtos não poluentes. Neste trabalho, é discutida a desativação de catalisadores automotivos devido às altas temperaturas de operação e por contaminação inorgânica originária dos combustíveis e óleos utilizados. Catalisadores novos e usados foram analisados por adsorção gasosa, picnometria, difração de raios X, e microscopia eletrônica de varredura para caracterizações texturais, morfológicas e estruturais. Microssonda eletrônica foi utilizada para detectar a composição dos catalisadores e dos seus contaminantes.
\end{abstract}

Palavras-chave: catalisador automotivo, caracterização textural.

\begin{abstract}
Catalytic converters or automotive catalyst are formed by noble metals such as platinum, rhodium, palladium, and molybdenum supported in cordierite, a porous ceramic materials which convert the pollutant gases in carbon dioxide, water and nitrogenous, no-pollutant products. In this work, we discuss the deactivation of automotive catalyst due to the high operation temperature and by inorganic contaminants originating in engine oil and fuel. New and used catalysts were analyzed by gas adsorption, picnometry, X-ray diffraction, thermal analyses and scanning electron microscopy for textural, morphological and structural characterization. EDS and WDS electron microprobe were used to detect the composition of the catalysts and their contaminants.
\end{abstract}

Keywords: automotive catalyst, textural characterization.

\section{INTRODUÇÃO}

A poluição do ar é crítica nos grandes centros urbanos, sendo por isso necessário melhorar o monitoramento das emissões, detectando as fontes potencialmente poluidoras com o objetivo da criação de estratégias sadias de gerenciamento desta poluição para proteção da saúde pública [1-5].

Com relação à poluição atmosférica, sabe-se que as emissões veiculares correspondem a parcelas significativas das emissões globais de agentes poluidores do ar. A conscientização do impacto destas emissões no ambiente conduziu à introdução de padrões de controle de emissão para os veículos a motor nos anos setenta do século passado. Nos EUA, esta legislação levou à redução das emissões veiculares dos principais poluentes gasosos, como monóxido de carbono (CO), hidrocarbonetos (HC) e óxidos de nitrogênio $\left(\mathrm{NO}_{\mathrm{x}}\right)$, mas devido ao aumento quase linear da produção mundial de veículos a motor, os benefícios advindos desta mudança passaram a ser pouco significativos [6-10]. Conseqüentemente, padrões mais restritivos de emissão foram adotados pela legislação, não somente nos EUA, mas também em outros países do mundo, como por exemplo, Japão e comunidade européia.

Até 1975, a maioria dos veículos não podia atender à legislação que previa alteração nas condições de funcionamento do motor. Os limites mais restritivos de emissão tornaram necessária a introdução de catalisadores 


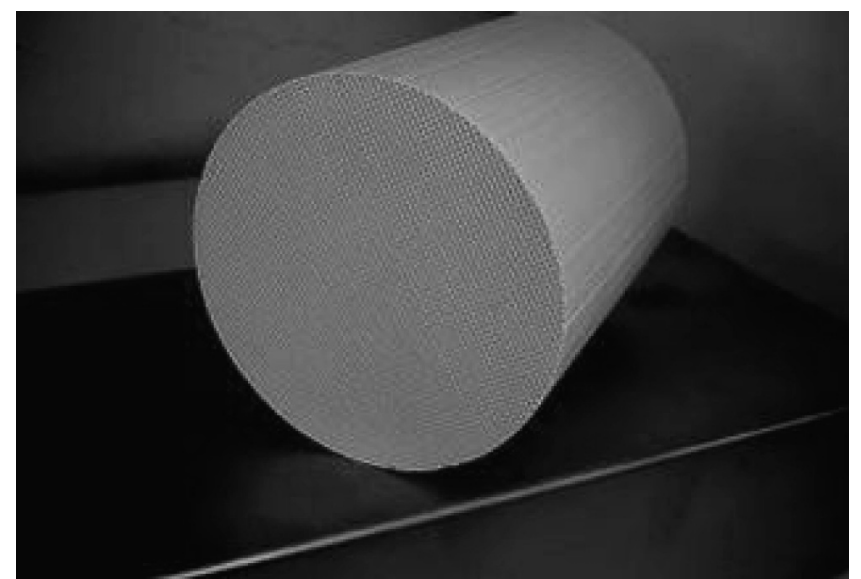

Figura 1: Monólito poroso de cordierita de magnésio.

[Figure 1: Honeycomb monolith of magnesium cordierite.]

heterogêneos baseados em metais nobres que evitavam a emissão excessiva de gases poluentes. Hoje em dia, no Brasil, os sistemas avançados de pós-tratamento de gases de exaustão de veículo à gasolina, por exigência da legislação, utilizam os catalisadores de três vias (TWC - Three-Way Catalyst) que podem reduzir as emissões do $\mathrm{CO}, \mathrm{HC}$ e de $\mathrm{NO}_{x}$ em mais de $90 \%$ por veículo [11-15].

Estes catalisadores são formados por monólitos de cordierita de magnésio $\left(2 \mathrm{MgO} .2 \mathrm{Al}_{2} \mathrm{O}_{3} .5 \mathrm{SiO}_{2}\right)$, com uma estrutura parecida à de uma colméia. Na superfície desta estrutura é aplicado um filme de $\gamma$-alumina, impregnado de metais nobres (principalmente platina, paládio e ródio) e outros aditivos, para melhorar a ação catalítica e estabilizar a alumina nas condições de operação [14].

Após um determinado período de tempo, dependendo das condições de operação do catalisador, este é desativado, devido principalmente a três fatores: envenenamento, formação de fuligem, e desativação térmica. O envenenamento é de natureza química, a formação de fuligem é um processo mecânico e a degradação térmica (sinterização ou transformação dos metais ativos) ocorre em função da temperatura [16-28].

O presente trabalho visa o estudo da influência da temperatura de utilização e da gasolina utilizada no Brasil na vida útil e desempenho do catalisador através de um estudo textural e de contaminantes inorgânicos na sua superfície ativa que, por envenenamento e ou por deposição de fuligem, podem comprometer o seu funcionamento.

\section{EXPERIMENTAL}

Foram confeccionados corpos de prova com catalisadores automotivos novos e usados de veículos à gasolina, obtidos da frota veicular de empresas que trabalham com escapamentos.

As fases formadoras da matriz e dos filmes foram verificadas por difração de raios $\mathrm{X}$. As amostras foram pulverizadas em gral de ágata e espalhadas homogeneamente sobre uma lâmina de vidro, utilizando-se álcool etílico como líquido dispersante. $\mathrm{O}$ equipamento utilizado foi o difratômetro Rigaku Geigerflex-3034, com tubo de cobre, tensão $40 \mathrm{kV}$, corrente $30 \mathrm{~mA}$, tempo $0,5 \mathrm{~s}$ e velocidade do goniômetro $2 \mathrm{grau} / \mathrm{min}$.

A detecção dos metais e contaminantes na estrutura da cordierita foi realizada por microanálise no equipamento Jeol JXA 8900RL equipado com detectores de energia dispersiva de raios $\mathrm{X}$ (EDS) e comprimento de onda dispersivo de raios $\mathrm{X}$ (WDS). As amostras do catalisador automotivo foram embutidas em resina, lixadas, polidas, e recobertas por carbono. Imagens para estudo da morfologia foram obtidas por microscopia eletrônica de varredura com elétrons secundários, no equipamento Jeol JSM 840. Neste caso as amostras foram embutidas em resina e recobertas por ouro.

A técnica de picnometria a hélio foi utilizada para determinação da densidade real dos materiais. Foram preparados pequenos corpos de prova de catalisadores novos e usados, que foram pesados em balança analítica antes da medida. As amostras foram submetidas a ensaios de adsorção gasosa com nitrogênio gasoso para medidas de área superficial específica e porosidade em um equipamento Autosorb Quantachrome Nova 1200, o qual é composto por um sistema de adsorção automatizado que fornece dados de equilíbrio de adsorção e dessorção. As amostras de catalisador automotivo novo e usado foram pesadas em uma célula previamente calibrada e desgaseificada por $3 \mathrm{~h}$ a 150 ${ }^{\circ} \mathrm{C}$ antes de cada ensaio. A incerteza do equipamento é de 5\%. As medidas de área superficial específica e porosidade foram baseadas nos princípios de Brunauer-Emmett-Teller (BET) e de Barrett, Joyner e Halenda (BJH), respectivamente.

\section{RESULTADOS E DISCUSSÃO}

Os difratogramas de raios $\mathrm{X}$ apresentados na Fig. 2 confirmam a presença da cordierita na constituição dos catalisadores automotivos novos e usados. Os outros

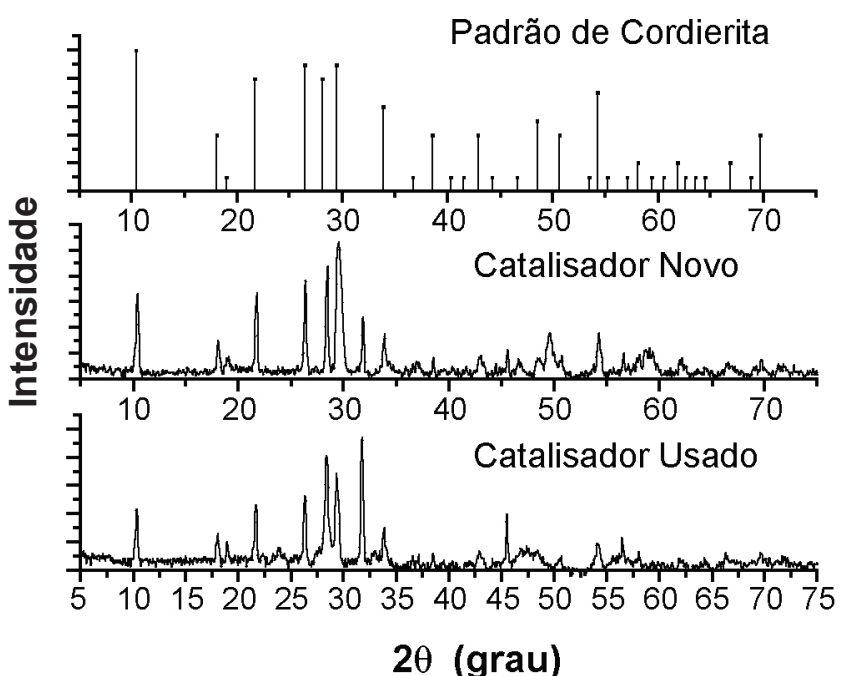

Figura 2: Difratograma de raios $\mathrm{X}$ dos catalisadores novos e usados.

[Figure 2: X-ray diffraction patterns of new and used catalysts.] 


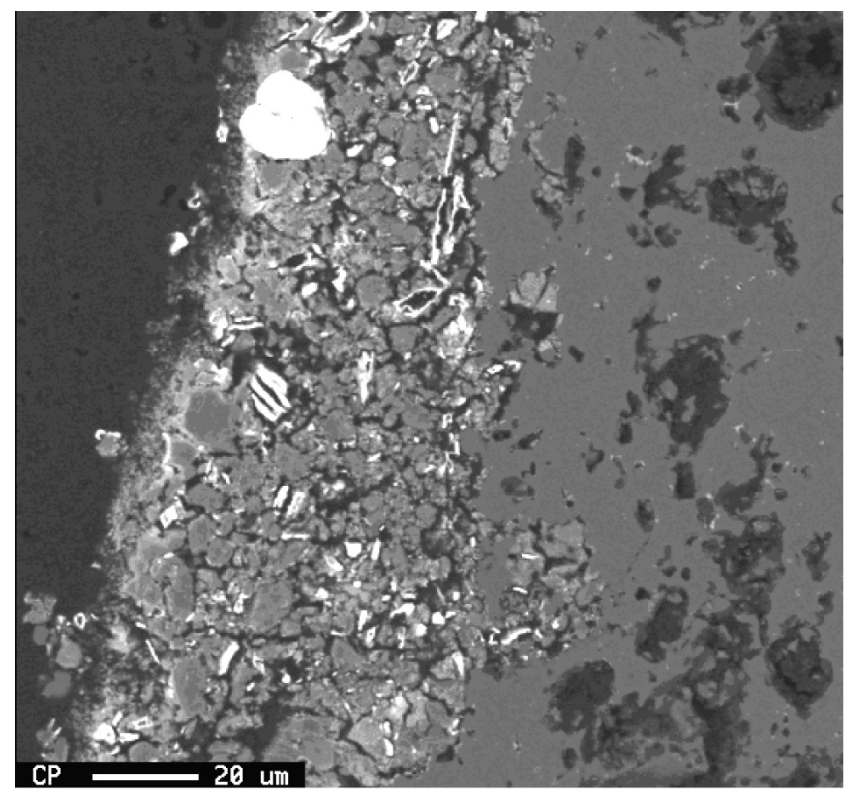

Figura 3: Imagem de um catalisador novo obtida por elétrons retroespalhados.

[Figure 3: New catalyst image obtained by backscattered electrons.]
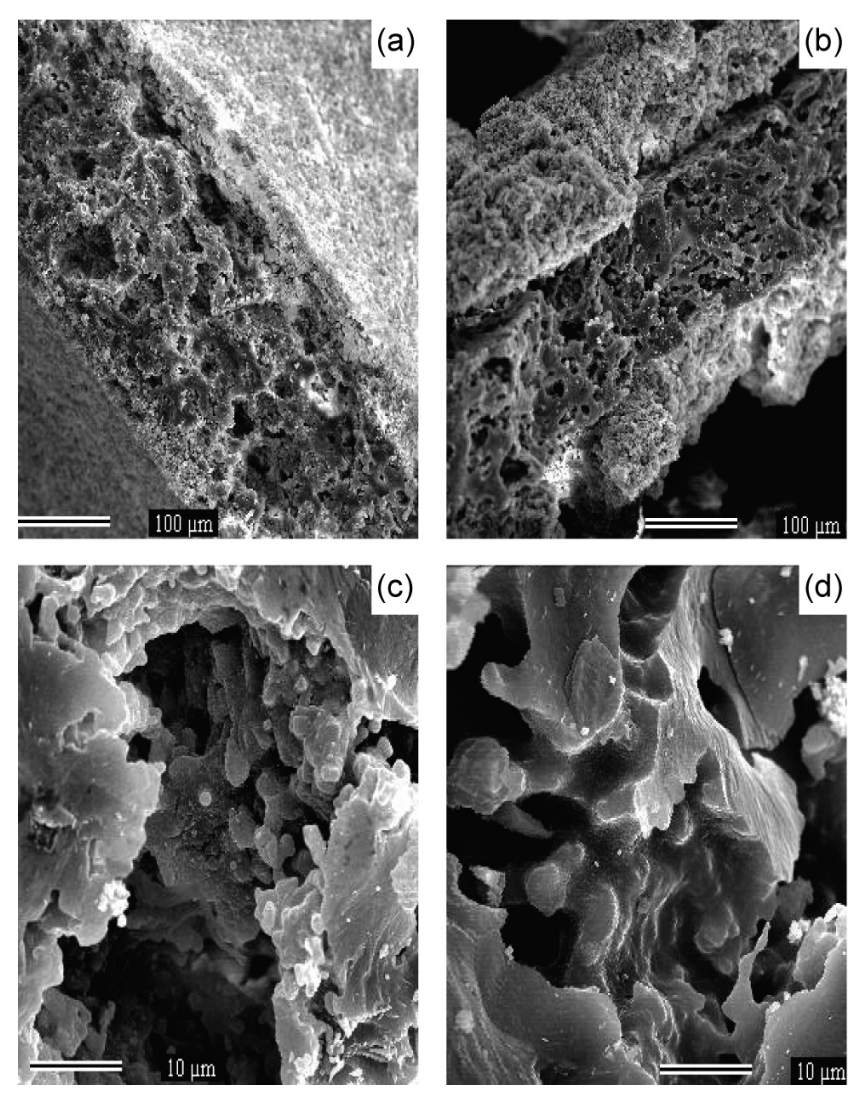

Figura 4: Micrografias obtidas por microscopia eletrônica de varredura de amostras de catalisador novo e usado. a) catalisador novo (aumento de 200x e 2000x); b) catalisador usado (aumento de 200x e 2000x)

[Figure 4: Scanning electron microscopy micrographs of new and used catalyst samples. a) new catalyst (200x and 2000x); b) used catalyst (200x e 2000x).] picos são característicos do filme de alumina e dos metais dispersos no mesmo. No difratograma do catalisador usado, constatou-se uma variação razoável, devido ao acúmulo de contaminantes no catalisador e oxidação dos metais nobres.

A Fig. 3 mostra uma imagem típica de elétrons retroespalhados obtidos por microscopia eletrônica de varredura, onde é possível observar a textura porosa do filme de alumina

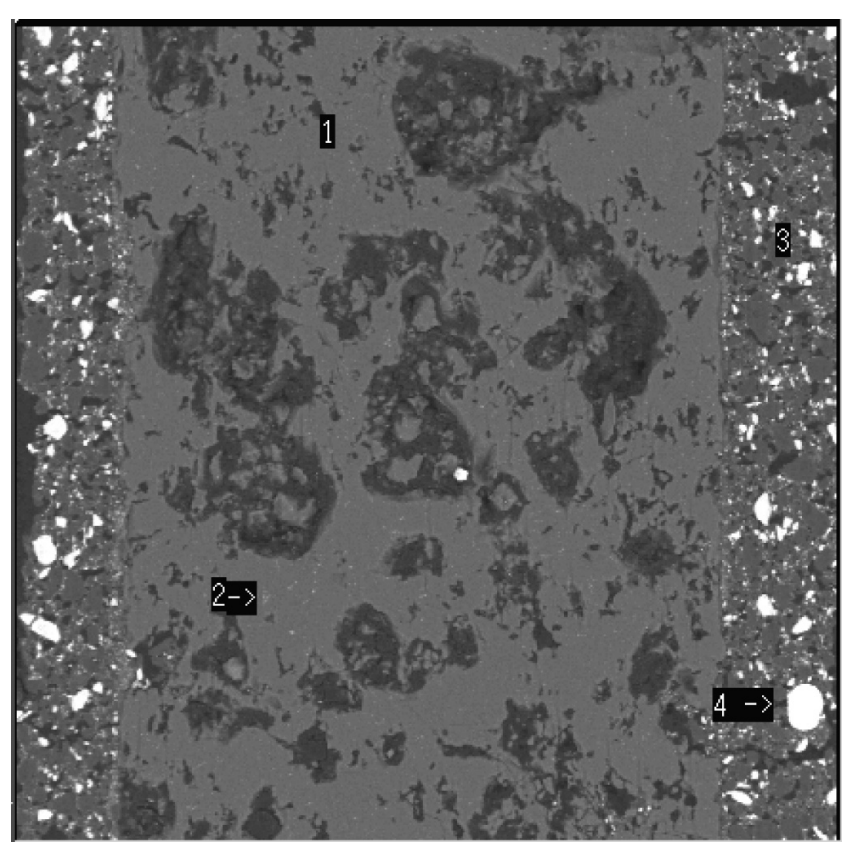

Figura 5: Micrografia obtida por microscopia eletrônica de varredura por elétrons retro-espalhados de um catalisador automotivo novo. 1 - cordierita; 2 - impureza da cordierita; 3 - filme de alumina; 4 metais e óxidos ativos.

[Figure 5: Backscattering SEM micrograph of new automotive catalyst. 1: cordierite, 2: cordierite impurities, 3: alumina film, 4: active metals and oxides.]

Tabela I: Caracterização elementar por WDS de amostra de catalisador novo.

[Table I: Element WDS characterization of new catalyst sample.]

\begin{tabular}{cc}
\hline Ferro $(\mathrm{Fe})$ & Cálcio $(\mathrm{Ca})$ \\
\hline Magnésio $(\mathrm{Mg})$ & Lantânio $(\mathrm{La})$ \\
\hline Paládio $(\mathrm{Pd})$ & Silí́cio $(\mathrm{Si})$ \\
\hline Bário $(\mathrm{Ba})$ & Cério $(\mathrm{Ce})$ \\
\hline Níquel $(\mathrm{Ni})$ & Zircônio $(\mathrm{Zr})$ \\
\hline Alumínio $(\mathrm{Al})$ & Fósforo $(\mathrm{P})$ \\
\hline
\end{tabular}

Tabela II - Caracterização elementar por WDS dos contaminantes na amostra de catalisador usado.

[Table II - Element WDS characterization of used catalyst sample.]

\begin{tabular}{lc}
\hline Potássio $(\mathrm{K})$ & Cloro $(\mathrm{Cl})$ \\
\hline Enxofre $(\mathrm{S})$ & Carbono $(\mathrm{C})$ \\
\hline
\end{tabular}




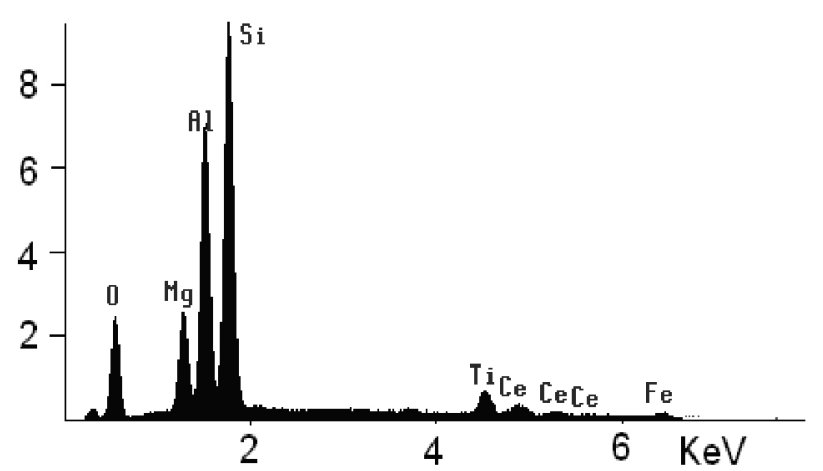

a) Ponto 1 - cordierita

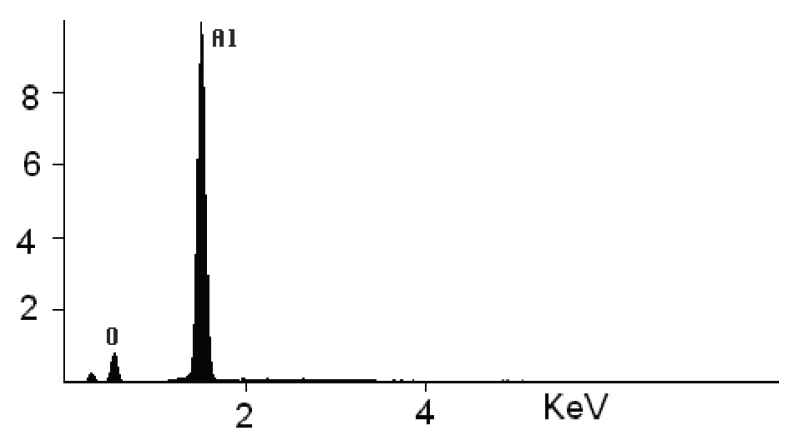

c) Ponto 3 - filme de alumina

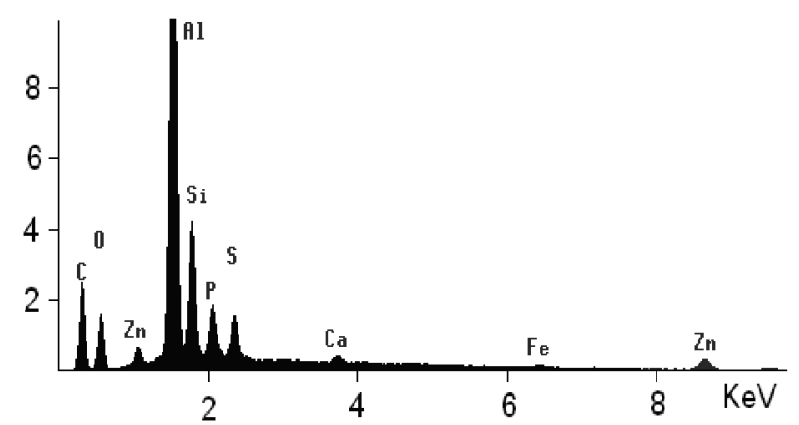

e) Ponto 3 - catalizador usado

Figura 6: Espectros EDS.

[Figure 6: EDS spectra.]

com metais ativos dispersos de forma heterogênea (pontos brancos) depositados sobre a cordierita. Os grãos de metais nobres variam de 1 a $15 \mu \mathrm{m}$. As imagens apresentadas na Fig. 4 permitem uma comparação do ponto de vista textural e morfológico entre um catalisador novo e um usado. $\mathrm{O}$ catalisador novo (Fig. 4a) apresenta uma forma definida, enquanto o usado (Fig. 4b) mostra uma superfície erodida com forma indefinida. No aspecto textural, estas diferenças ficam mais acentuadas, já que o catalisador usado apresenta uma grande diminuição da porosidade devido a um início de sinterização, em relação ao catalisador novo.

A Fig. 5 mostra uma imagem de um catalisador novo obtida por elétrons retro-espalhados em amostra polida, cujas bordas correspondem ao catalisador propriamente dito de alumina porosa, evidenciando a distribuição heterogênea dos metais ativos (pontos brancos) no filme de alumina. Os

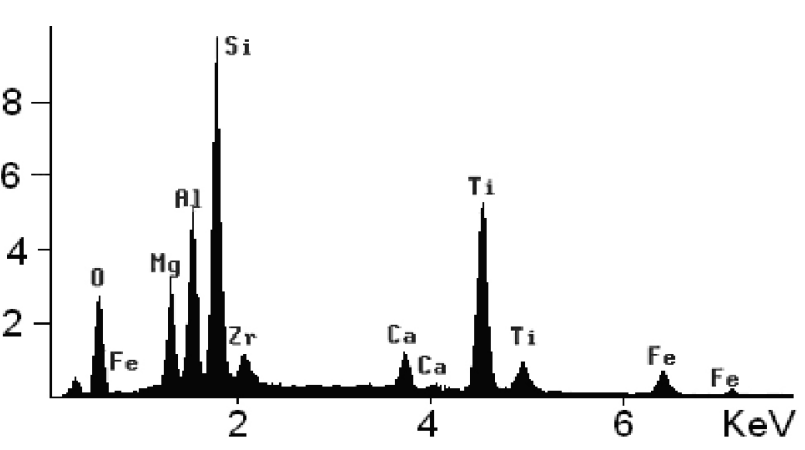

b) Ponto 2 - cordierita

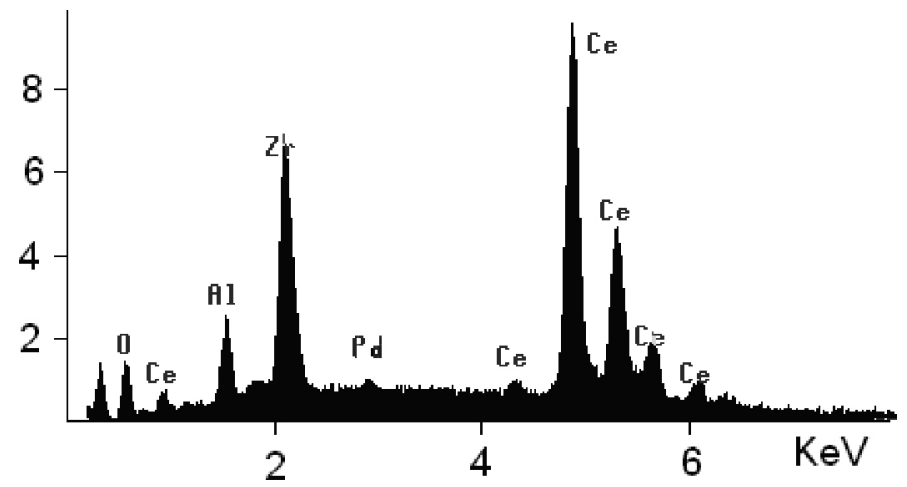

d) Ponto 4 - metais e óxidos ativos

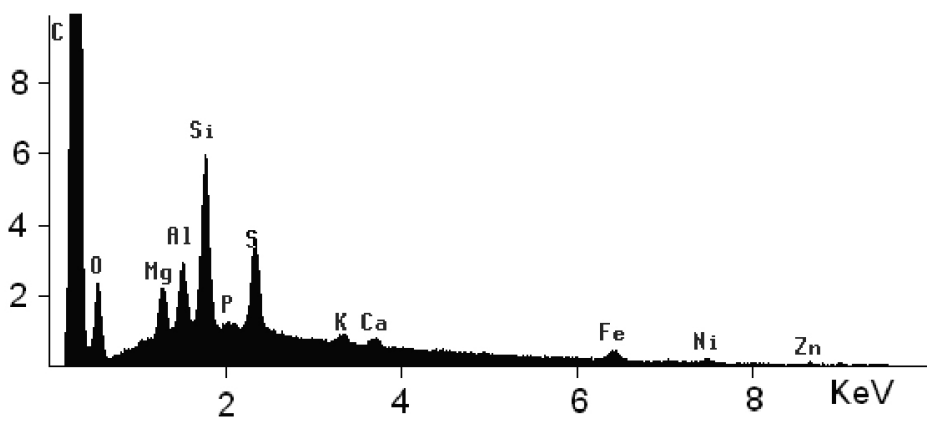

f) fuligem

pontos marcados foram analisados com o detector EDS (Fig. 6), confirmando as composições elementares esperadas da cordierita no espectro $6 \mathrm{a}(\mathrm{Al}, \mathrm{Mg}$ e $\mathrm{Si})$ referentes à região 1. A região 2 também apresenta a composição da cordierita com algumas impurezas como $\mathrm{Ti}, \mathrm{Fe}, \mathrm{Ca}$ e $\mathrm{Zr}$ (espectro 6b). $\mathrm{O}$ filme de alumina mostrou-se puro (região 3 , espectro $6 \mathrm{c}$ ) contendo metais dispersos, como o cério $(\mathrm{Ce})$ em maior quantidade e traços de paládio $(\mathrm{Pd})$ caracterizados pela região 4 e espectro 6d. Amostras de vários catalisadores novos e usados foram caracterizadas, e não foi encontrado vestígio de platina $(\mathrm{Pt})$. As análises realizadas pela sonda WDS (Tabela I) confirmam estes resultados. Os catalisadores usados apresentaram a mesma composição dos catalisadores novos mais contaminantes como carbono, potássio, enxofre e cloro que podem ser provenientes tanto da gasolina como do óleo lubrificante do motor (Tabela II e espectro 6e). 

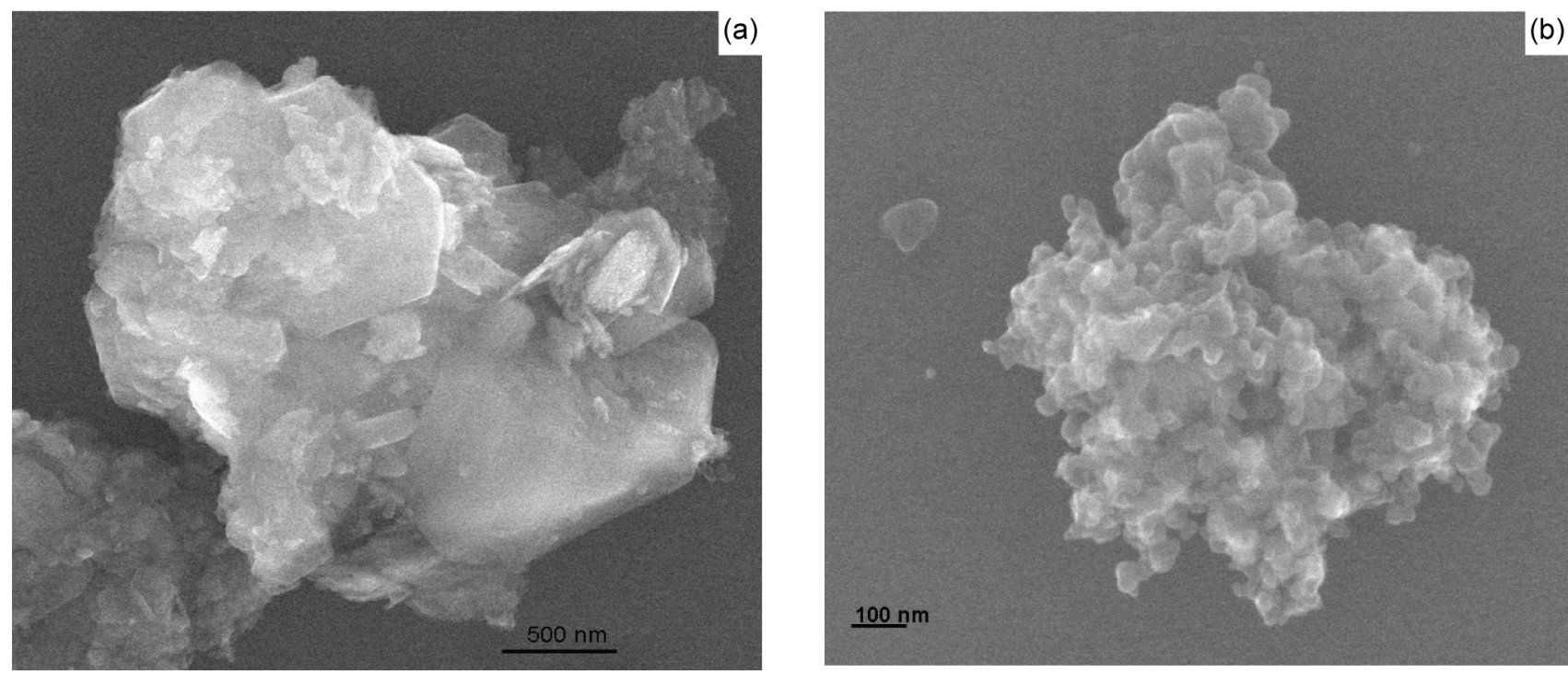

Figura 7: Imagens de material particulado retirados dos catalisadores automotivos usados.

[Figure 7: Image of particulate material removed by used automotive catalysts.]
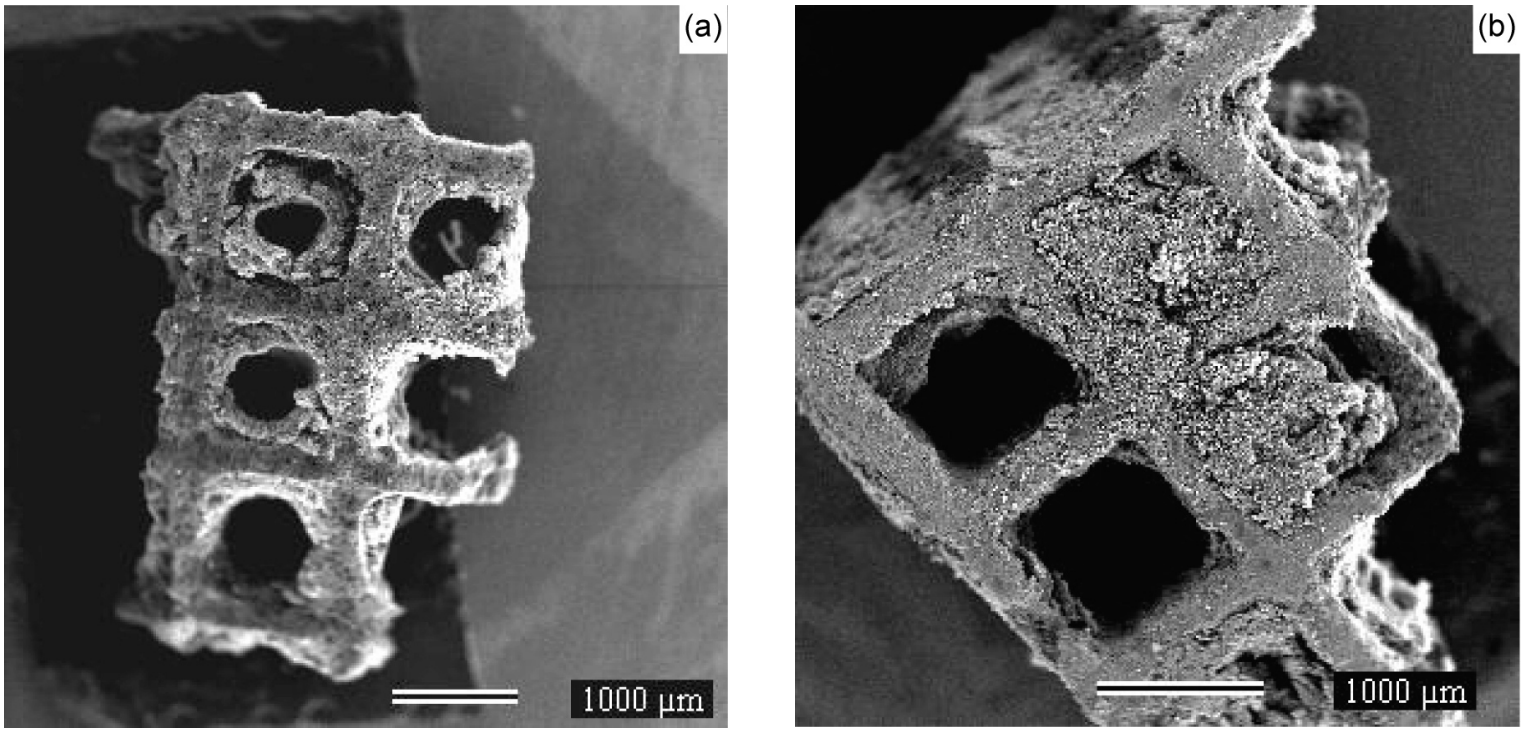

Figura 8: Micrografia MEV de um catalisador usado, evidenciando a obstrução das estruturas das colméias. [Figure 8: Used catalyst SEM micrograph showing the obstruction of the honeycomb structure.]

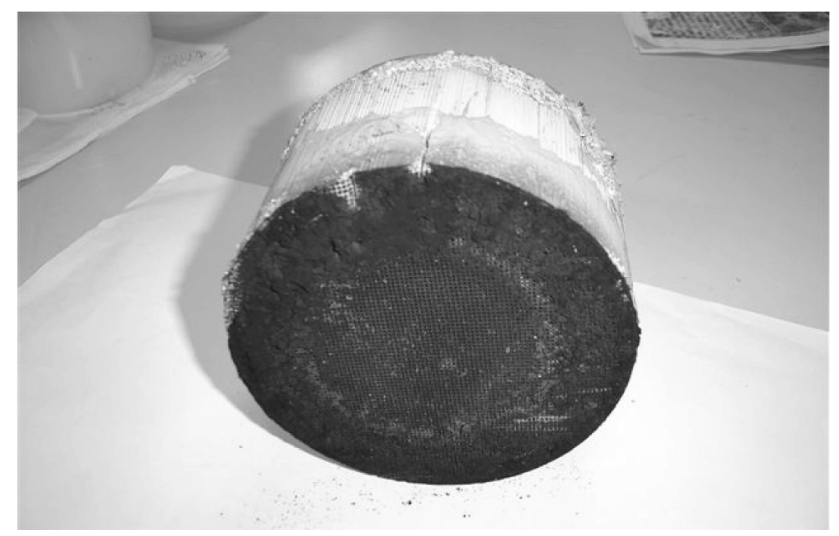

Figura 9: Catalisador usado totalmente contaminado com fuligem. [Figure 9: Used catalyst contaminated by soot.]
Amostras de fuligem coletada de vários catalisadores foram analisadas por MEV e EDS, e mostraram grande quantidade de carbono, enxofre, silício, alumínio e magnésio, além de quantidades menores de fósforo, ferro e níquel (espectro 6f). A fuligem tem característica de material particulado, com tamanhos variando de $25 \mathrm{~nm}$ a $2 \theta / \mathrm{min}$, como mostra a Fig. 7. Observamos partículas da ordem de micra (Fig. 7a), e partículas da ordem de $25 \mathrm{~nm}$ dispersas e formando aglomerados da ordem de nanômetros (Fig. 7b).

As imagens nas Figs. 8 e 9 ilustram a obstrução por contaminantes (fuligem) de catalisadores usados. As partículas de fuligem penetram nos poros do catalisador, além de obstruir os canais do monólito de cordierita.

Para a realização de análises de picnometria a hélio e de adsorção de gases, o catalisador usado foi submetido a 
Tabela III - Dados de picnometria a hélio e de adsorção gasosa.

[Table III - Helium picnometer and gas adsorption analysis data.]

\begin{tabular}{ccccc}
\hline $\begin{array}{c}\text { Amostra } \\
\text { de } \\
\text { catalisador }\end{array}$ & $\begin{array}{c}\text { Aensidade } \\
\left(\mathrm{g} / \mathrm{cm}^{3}\right)\end{array}$ & $\begin{array}{c}\text { Volume } \\
\text { superficial } \\
\text { específica } \\
\left(\mathrm{m}^{2} / \mathrm{g}\right)\end{array}$ & $\begin{array}{c}\text { Diâmetro } \\
\text { total } \\
\left(10^{-3} \mathrm{~cm}^{3} / \mathrm{g}\right)\end{array}$ & $\begin{array}{c}\text { médio } \\
\text { dos poros } \\
(\hat{\mathrm{A}})\end{array}$ \\
\hline Novo & $3,1 \pm 0,1$ & $58 \pm 3$ & $141 \pm 7$ & $110 \pm 5$ \\
Usado & $3,6 \pm 0,1$ & $9 \pm 1$ & $36 \pm 2$ & $39 \pm 2$ \\
\hline
\end{tabular}
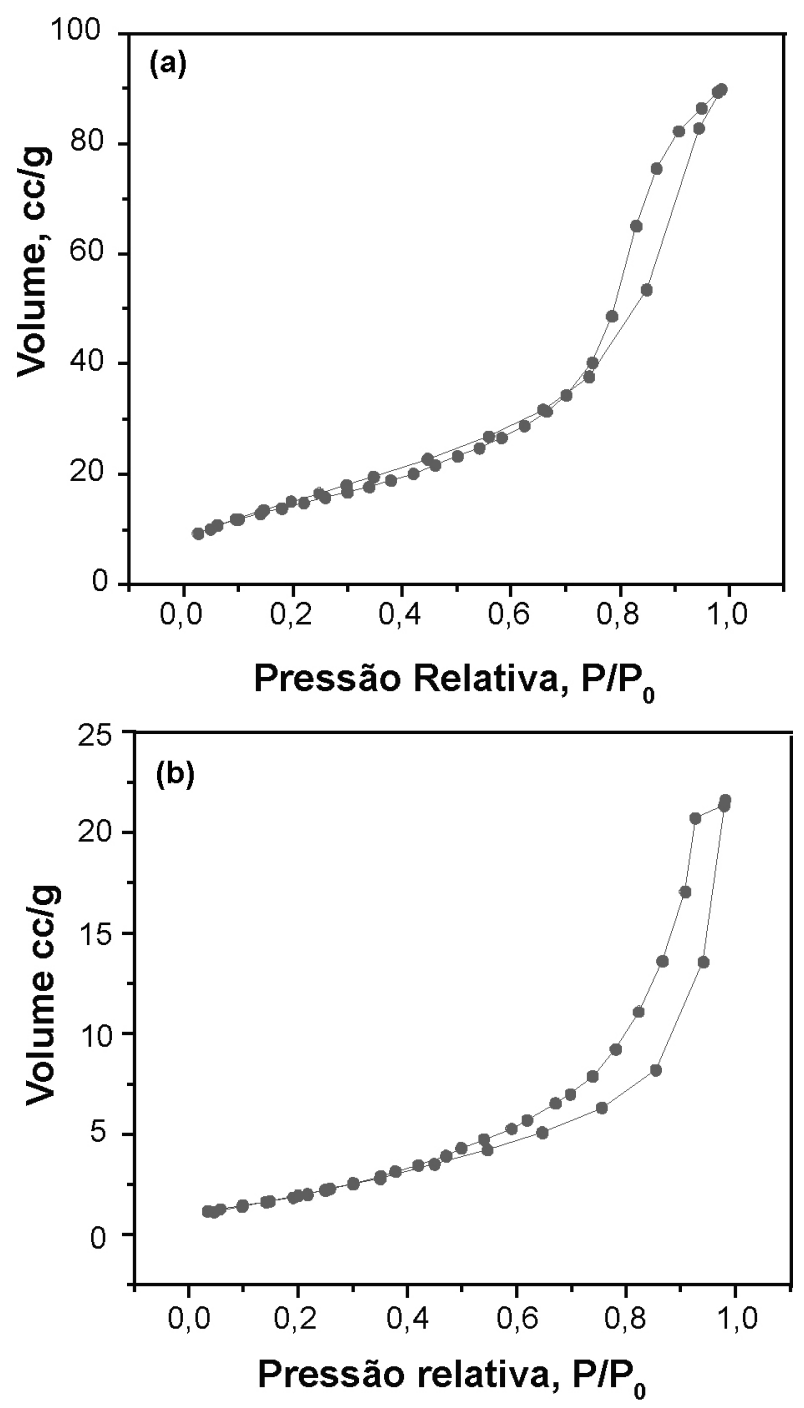

Figura 10: Isotermas de adsorção e dessorção de amostras de catalisador: a) novo e b) usado.

[Figure 10: Adsorption-desorption isotherms of catalyst samples: a) new and b) used.]

uma limpeza com a finalidade de eliminar a maior parte da fuligem presa nas colméias. Permaneceu apenas a fuligem adsorvida nos poros do catalisador. A Tabela III mostra os valores de densidades obtidos por picnometria a hélio e área superficial específica, volume total de poros e diâmetro médio de poros obtidos por adsorção gasosa. A densidade do catalisador usado é bem maior que a do catalisador novo, o que condiz com o processo de sinterização sofrido pelo catalisador após utilização em temperaturas elevadas.

O catalisador usado apresenta valores texturais bem inferiores aos do catalisador novo, comprovando também o processo de sinterização que provoca a desativação do catalisador. Tanto a área superficial específica como o volume total de poros e o tamanho médio de poros sofrem grandes variações após a utilização. As duas isotermas de adsorção e dessorção (Fig. 10) são características de materiais mesoporosos (isoterma tipo IV, conforme classificação da IUPAC) e mostram que a amostra de catalisador novo adsorveu um volume de gás nitrogênio bastante superior comparada à amostra de catalisador usado. A forma da isoterma mostra uma grande mudança na forma dos poros, o que comprova a maior porosidade e diâmetro dos poros do catalisador novo em relação ao usado.

\section{CONCLUSÕES}

A caracterização dos catalisadores automotivos novos e usados utilizando diversas técnicas forneceu resultados importantes, mostrando a contaminação química do catalisador por enxofre e carbono e o entupimento dos poros do catalisador por grande quantidade de fuligem, que evidencia a quantidade de enxofre contida na gasolina brasileira. Estes dois fenômenos sugerem a desativação química e mecânica. As grandes variações texturais devido à exposição do catalisador a altas temperaturas, promovendo inclusive um início de sinterização, mostrou que o filme de alumina utilizado no catalisador não tem estabilidade térmica a altas temperaturas.

Os catalisadores poderiam também ser mais eficientes se os metais nobres tivessem tamanhos menores, fossem mais homogêneos e estivessem mais dispersos nos filmes de alumina. O filme utilizado deveria também ser mais estável em altas temperaturas.

\section{AGRADECIMENTOS}

Os autores agradecem ao CNPq pelo apoio financeiro.

\section{REFERÊNCIAS}

[1] G. C. Koltsakis, A. M. Stamatelos, Prog. Energy Combust. Sci. 23 (1997)

[2] F. Oudet, P. Courtine, A. Vejun, J. Catal. 114 (1988) 112.

[3] T. Horiuchi, Y. Teshima, T. Osaki, T. Sugiyama, K. Suzuki, T. Mori, Catal. Lett. 62 (1999) 107.

[4] F. Mizukami, K. Maeda, M. Watanabe, K. Masuda, T. Sano, K. Kuno, Thermostable high-surface-area aluminas and properties of the alumina-supported Pt catalysts, in A. Crucg (Ed.), Catalysis and Automotive Pollution Control, 
Elsevier, Amsterdam, Holanda, 2 (1991) 557.

[5] L. L. Murrell, S. J. Tauster, Sols as precursors to transitional aluminas and these aluminas as host supports for $\mathrm{CeO}_{2}$ and $\mathrm{ZrO}_{2}$ microdomains, in A. Crucg (Ed.), Catalysis and Automotive Pollution Control, Elsevier, Amsterdam, Hoçanda, 2 (1991) 547.

[6] N. A. Koryabkina, R. A. Shkrabina, V. A. Ushakov, M. Lausberg, F. Keptein, Z. R. Ismagilov, Kinet. Catal. 38 (1997) 112.

[7] Z. R. Ismagilov, R. A. Shkrabina, N. A. Koryabkina, D. A. Arendarskii, N. V. Shikina, Preparation of thermally stable washcoat aluminas for automotive catalysts, in N. Kruse, A. Frennet, J. M. Bastin (Eds.), Catalysis and Automotive Pollution Control, Elsevier, Amsterdam, Holanda, 4 (1998) 507.

[8] R. Di Monte, P. Fornasiero, J. Kaspar, M. Graziani, J. M. Gatica, S. Bernal, Gomez-Herrero, Chem. Comm. 21 (2000) 2167.

[9] A. Piras, A. Trovarelli, G. Dolcetti, Appl. Catal. B 28 (2000) L77.

[10] D. N. Tsinoglou, G. C. Koltsakis, Chem. Eng. Sci. 58 (2003), 179.

[11] N. A. Koryabkina, R. A. Shkrabina, V. A. Ushakov, E. M. Moroz, M. F. Lansberg, Z. R. Ismagilov, Kinet. Catal. (Engl. Transl.) 37 (1996) 117.

[12] C. Morterra, G. Magnacca, V. Bolis, G. Cerrato, M. Barricco, A. Giachello, M. Fucale, Structural, morphological and surface chemical features of $\mathrm{Al}_{2} \mathrm{O}_{3}$ catalyst supports stabilized with $\mathrm{CeO}_{2}$, in A. Frennet, J. M. Bastin (Eds.), Catalysis and Automotive Pollution Control, Elsevier, Amsterdam, Holanda, 3 (1995) 361.

[13] C. Morterra, V. Bolis, G. Magnacca, J. Chem. Soc., Faraday Trans. 92 (1996) 1991.
[14] J. Z. Shyu, K. Otto, W. L. H. Watkins, G. W. Graham, R. K. Belitz, H. S. Gandhi, J. Catal. 114 (1988) 23.

[15] J. Z. Shyu, W. H. Weber, H. S. Gandhi, J. Phys. Chem. 92 (1988) 4964.

[16] J. M. Dominguez, J. L. Hernandez, G. Sandoval, Appl. Catal. A 197 (2000) 119.

[17] H. S. Gandhi, A. G. Piken, M. Shelef, R. G. Delosh, SAE Paper 760201 (1976) 55.

[18] M. Sideris, Methods for Monitoring and Diagnosing the Efficiency of Catalytic Converters: A Patent Oriented Survey, Elsevier, Amsterdam, Holanda, 115 (1997).

[19] F. B. Noronha, M. C. Durão, M. S. Batista, L. G. Appel, Catal. Today 85 (2003) 13.

[20] P. Burtin, J. P. Brunelle, M. Pijolat, M. Soustele, Appl. Catal. 34 (1987) 239.

[21] C. Larese, F. C. Galisteo, M. L. Granados, R. Mariscal, J. L. G. Fierro, M. Furió, R. F. Ruiz, Appl. Catal. B: Environ. 40 (2003) 305.

[22] H. S. Gandhi, M. Shelef, Appl.Catal. 77 (1991) 175.

[23] D. D. Beck, J.W. Sommers, Appl.Catal. B: Environ. 6 (1995) 185.

[24] J. T. Kummer, Progress in Energy and Combustion Science 6, 2 (1980) 177.

[25] T. Luo, J. M. Vohs, R. J. Gorte, J. Catal. 210 (2002) 397.

[26] D. D. Beck, J. W. Sommers, C. L. DiMaggio, Appl. Catal. B 11 (1997) 273

[27] J. S. Hepburn, D. A. Dobson, C. P. Hubbard, S. O. Guidberg, E. Thanasiu, W. L. Watkins, B. D. Burnsand, H. S. Gandhi, SAE Paper 942057 (1994).

[28] R. Maria do Carmo, M. F. A. Carvalho, Química. Nova 26, 2 (2003) 265

(Rec. 04/08/2008, Ac. 24/10/2008) 